\title{
NO OLHO DO FURACÃO: CELSO FURTADO E FRANCISCO DE OLIVEIRA NOS PRIMEIROS ANOS DA SUDENE*
}

\author{
Flávio da Silva Mendes \\ é pós-doutorando em Sociologia na Universidade Estadual de Campinas (Unicamp). \\ Campinas, SP. Brasil.E-mail:<flavio85@gmail.com>
}

http://dx.doi.org/10.1590/ 0102-283311/100

A história dos primeiros anos da Superintendência do Desenvolvimento do Nordeste (Sudene) - sobretudo do período que se estende de sua criação, em 1959, ao golpe de 1964 - revela parte importante do debate intelectual e político que envolveu o auge e a crise do nacional-desenvolvimentismo no Brasil. Muitos autores já se dedicaram a esse tema $^{1}$, ao qual retorno neste artigo a partir da análise da trajetória de dois personagens que viveram de forma intensa aqueles anos: o economista Celso Furtado, mentor e líder natural da chamada Operação Nordeste, que deu origem à Sudene, e o então recém-formado sociólogo Francisco de Oliveira, integrante do primeiro grupo de servidores da Superintendência. Nos escritórios desse órgão, no Recife,

\footnotetext{
* Este artigo apresenta de forma resumida alguns resultados de pesquisa de doutorado em Sociologia (Mendes, 2015). Agradeço à Capes e à Fapesp pela concessão de bolsas que permitiram a realização deste trabalho.

1 Entre esses trabalhos, dois dos mais importantes foram escritos por Celso Furtado e Francisco de Oliveira. Do economista, destaca-se o livro A fantasia desfeita (Furtado, 1989). Do sociólogo, o ensaio Elegia para uma re(li)gião (Oliveira, 2008). Também são referências para este trabalho as obras de Bielschowsky (2004), Callado (1979), Cardoso (1978), Garcia (1998), Mantega (1984), Soares (1982) e Tavares (1989).
} 
ambos compartilharam a experiência de colocar em prática um programa que pretendia revolucionar a forma como o Estado brasileiro tratava a questão regional, o que os obrigava a lidar, ao mesmo tempo, com os interesses de oligarquias decadentes e as demandas de movimentos populares em ascensão. Contexto favorável ao conflito, como lembrou Oliveira em entrevista:

Foi a melhor experiência pessoal que tive. Trabalhar no olho do furacão. Porque estava no Nordeste, eram as Ligas Camponesas de um lado, o "diabo a quatro" de outro, a pressão sobre a Sudene era violentíssima. A gente estava no meio de quatro ou cinco fogos, não era apenas um lado. Tinha a Liga Camponesa de um lado e a Igreja Católica, que era muito ativa, do outro. E um movimento estudantil muito forte. A burguesia açucareira - que estava querendo retomar o tempo perdido - foi importante, os latifundiários. $\mathrm{O}$ Partido Comunista era forte, com um pé atrás: desconfiava do Celso [Furtado], mas apoiava. Então era um pau só (Jinkings, Ridenti e Maar, 2007, pp. 18-19).

Apesar de logo ter se tornado o substituto direto de Furtado na direção do órgão, Oliveira não exercia grande influência sobre sua agenda política. Esta era concebida a partir das pesquisas que o economista, já consagrado, dedicara aos problemas do subdesenvolvimento e, claro, às pressões da conjuntura. Apenas anos mais tarde, já na década de 1970, o sociólogo se sentiria à vontade para criticar aquele programa: ligado ao Centro Brasileiro de Análise e Planejamento (Cebrap), em São Paulo, um dos mais importantes núcleos de produção das ciências sociais brasileiras durante a ditadura, Oliveira se tornaria uma grande referência nos debates sobre o desenvolvimento nacional. A diferença de prestígio de que desfrutavam nos primeiros anos da Sudene não impede a análise proposta neste artigo; ao contrário: 
a exposição de suas trajetórias distintas nos permite enxergar vários aspectos importantes daquele contexto.

\section{Celso Furtado ou "o profeta de fraque"}

Nascido na cidade de Pombal, no sertão da Paraíba, em 1920, Celso Furtado concluiu seus estudos secundários no Recife e cursou direito no Rio de Janeiro, então capital do país, entre 1939 e 1943. Aos 27 anos - em 1948, obteve um doutorado em economia em Paris e, em 1958, concluiu um pós-doutorado na mesma disciplina em Cambridge. Sua trajetória acadêmica inicial, na graduação, assemelha-se àquela de outros economistas renomados de sua geração, os quais, em geral, obtinham um diploma em direito ou engenharia, carreiras mais tradicionais, e entravam em contato com a economia mais tarde, na prática. Além da carência de cursos dedicados a essa disciplina ${ }^{2}$, o percurso por outras áreas refletia a frágil divisão profissional do período, que seria mais bem definida apenas a partir dos anos 1960. Mas as demais etapas da formação de Furtado o distinguiam de outros membros de sua geração ou da imediatamente anterior: as duas pós-graduações na Europa e o espaço já ocupado na Comissão Econômica para a América Latina (Cepal), onde fora diretor da Divisão de Desenvolvimento, o tornavam "dotado de uma formação universitária em economia, de diplomas e de uma rede de colegas em nível internacional bastante raros" (Garcia, 1998, p. 54). Assim, ao articular uma formação tradicional no país com estudos e uma rede de contatos no exterior, Furtado conquistara uma legitimidade particular que lhe permitia entrar no debate entre

\footnotetext{
2 "As faculdades de economia não são criadas antes de 1938 (setor privado) e de 1945 (setor público, no Rio de Janeiro), mas até a metade dos anos 1960 sua clientela é composta, sobretudo, por estudantes de origem social bem inferior àquela dos membros da alta administração ou dotados de um capital escolar de menor valor: seus diplomas abriam caminho para o cargo de contador em empresas industriais, comerciais ou bancárias em expansão" (Garcia, 1998, p. 53).
} 
monetaristas e estruturalistas, então em voga, numa posição privilegiada: não pertencia ao grupo social onde se situava a maioria dos primeiros, em geral nascidos no Rio de Janeiro, filhos de grandes comerciantes ou de profissionais liberais, cosmopolitas, engenheiros de formação, perfil bem exemplificado por Eugênio Gudin. E mesmo tendo nascido no Nordeste e se formado em direito, como muitos dos economistas estruturalistas, filhos de famílias em declínio econômico, Furtado possuía, graças à sua formação mais ampla, recursos que eram exclusivos dos economistas liberais ${ }^{3}$.

Talvez essa dupla oposição (ou proximidade) aos dois polos do campo dos economistas em constituição possa nos ajudar a compreender como seus estudos universitários e sua carreira profissional o levaram a um investimento no universo da pesquisa econômica internacional bem superior àquele dos herdeiros das grandes famílias cosmopolitas, bem como ao empenho posterior na renovação das perspectivas de sua região de origem com os instrumentos adquiridos na cena cultural e política internacional (Garcia, 1998, p. 54).

No final dos anos 1940, já ligado à Cepal, Furtado conheceu de perto as teses do argentino Raúl Prebisch sobre as causas do atraso econômico latino-americano, cuja solução, pensavam, dependia primordialmente do incentivo à industrialização. Nos anos seguintes, com Prebisch à frente da Comissão, as teses desenvolvimentistas ganharam destaque internacional e passaram a influenciar a agenda política de diversos países. Furtado deu uma contribuição importante nesse sentido ao abrir caminho para a publicação de textos do argentino no Brasil e, também, ao colaborar na formulação da noção de subdesenvolvimento, fundamental para

\footnotetext{
3 Essa distinção entre economistas liberais e estruturalistas, bastante marcada entre os anos 1930 e 1964 no Brasil, é realizada por Loureiro (1997), especialmente no primeiro capítulo.
} 
a compreensão das particularidades da expansão capitalista na América Latina. No clássico Formação econômica do Brasil (Furtado, 1980 [1959]), ele aponta dois grandes desafios no caminho da consolidação do Estado nacional brasileiro: a integração do parque industrial e o combate às crescentes disparidades regionais (Garcia, 1998, pp. 56-57).

Quando retornou ao país, em 1958, Furtado encontrou cenário favorável às suas ideias. Naquele ano, uma grande seca atingira o Nordeste, o que expunha mais uma vez a ineficácia da intervenção do governo federal na região. No início do ano seguinte, numa reunião realizada no Palácio Rio Negro, em Petrópolis, convocada pelo Presidente Juscelino Kubitschek, o economista teve a oportunidade de expor seus planos para o desenvolvimento do Nordeste e criticar o modelo até então aplicado, que, segundo ele, encarava o problema das secas de forma equivocada. Para Furtado, não era a seca a verdadeira fonte de grandes e repetidas tragédias, como a recém-ocorrida. Aquelas situações de calamidade se originavam da inadequação da estrutura produtiva e social nordestina a esse fenômeno natural inevitável. O economista invertia, assim, o problema e apontava a monocultura da cana-de-açúcar como origem do fenômeno social - e não meramente natural - das secas na região.

O diagnóstico preciso atraiu a atenção do presidente, que naquele momento se empenhava na construção de Brasília, enquanto notava com preocupação a perda de apoio ao seu governo entre as elites nordestinas. A política pernambucana era um caso à parte, mas também preocupante: no estado se destacava o crescimento da chamada Frente do Recife, a partir da eleição de Pelópidas da Silveira para a prefeitura da capital, em 1955, com o apoio de socialistas e comunistas ${ }^{4}$. Motivos não faltavam, portanto, para aquela

\footnotetext{
4 A Frente do Recife se inseria num movimento político mais amplo: "Em 1955, mesmo ano de fundação das primeiras Ligas [Camponesas] em Pernambuco, reuniu-se no Recife o Congresso de Salvação do Nordeste, congregando as mais
} 
reunião do Palácio Rio Negro, a qual contou, segundo Furtado, com um grupo de convidados bem heterogêneo, "indo de Dom Helder Câmara ao industrial Israel Klabin". No entanto, ausências como a de Dom Helder, um dos líderes dos debates sobre os problemas do Nordeste dentro da Igreja, foram para Furtado um evidente sinal de ceticismo diante da proposta de Kubitschek. Entre os presentes, faltava iniciativa, o que deu a Furtado bastante tempo para expor suas ideias. Surpreso com o que ouviu, o presidente deu de imediato ao economista a tarefa de formular um plano e amadurecer a Operação Nordeste (Furtado, 1989, pp. 41-45). Esta culminaria na fundação do Conselho de Desenvolvimento do Nordeste (Codene), ainda em 1959, que deveria iniciar suas atividades enquanto a criação da Sudene não fosse aprovada pelo Congresso Nacional.

Kubitscheck, sem dúvida, pretendia reverter a má impressão que seu governo inspirava entre políticos do Nor288 deste, região que até então parecia não fazer parte dos seus audaciosos planos para o desenvolvimento nacional ou, na melhor das hipóteses, figurava neles como mera coadjuvante. Mas a Sudene não surgiria apenas como uma tentativa de maquiagem tardia, destinada a ofuscar o descaso anterior. A revisão dos fatos que envolveram sua criação revela que as ideias apresentadas por Celso Furtado ao presidente se alinhavam perfeitamente à ideologia desenvolvimentista que orientava o governo desde sua primeira "Mensagem ao Congresso Nacional". Nela, Kubitscheck afirmava que a economia brasileira deveria realizar a transição do "estágio predominantemente agropecuário, para o estágio da industrialização

diversas forças políticas, sociais e econômicas, em uma verdadeira frente ampla em defesa de uma nova política para a região. No ano seguinte, a Conferência Nacional dos Bispos do Brasil, realizou um encontro em Campina Grande, no qual a questão regional esteve na ordem do dia, indicando também em suas conclusões a necessidade de um outro tratamento para a região" (Bernardes, 2007, pp. 70-71; grifo no original). 
intensiva" e com esse processo acelerado de crescimento via industrialização viria o aumento da riqueza e do bem-estar da população ${ }^{5}$. É notável a semelhança entre esse programa, as esperanças que o envolviam e ideias que guiavam o trabalho de Celso Furtado. Logo, o que ocorreu no Palácio Rio Negro foi o casamento de dois discursos de mesma ideologia: o desenvolvimentismo. A simpatia do governo por aquela agenda provava que ela não se restringia ao debate teórico. Mais além: a força política que ela conquistara extrapolava a conjuntura nacional, em sintonia com mudanças importantes que ocorriam no capitalismo desde o final da Segunda Guerra Mundial, com destaque à migração de grande volume de capital dos países centrais para os do chamado Terceiro Mundo e a nova configuração do imperialismo durante a Guerra Fria. Guido Mantega (1984, p. 2) sintetizou bem o contexto que favoreceu a emergência daquele programa:

[...] o ideário desenvolvimentista surge por ocasião desse cruzamento entre o avanço das relações de produção e forças produtivas capitalistas nos países de ponta da América Latina e a solidificação da etapa mais avançada do imperialismo. A rigor o desenvolvimentismo não foi apenas o principal intérprete das novas forças socioeconômicas da "periferia", mas foi também o padrinho da feliz união entre a acumulação industrial local e o novo imperialismo. Em outras palavras, esse ideário não se limitou às fronteiras da produção teórica acadêmica, mas enveredou para o campo da política econômica, do planejamento governamental e inspirou a formulação de "planos de desenvolvimento".

Apesar de hegemônico, o desenvolvimentismo era uma ideologia muito ampla e, portanto, não homogênea. Assim

\footnotetext{
5 Um estudo detalhado do discurso desenvolvimentista do governo Kubitscheck foi realizado por Cardoso (1978).
} 
Bielschowsky (2004, p. 33) o define como: um plano "de superação do subdesenvolvimento através da industrialização integral, por meio de planejamento e decidido apoio estatal”. $\mathrm{Na}$ defesa desse programa básico, se engajavam vários setores da sociedade brasileira, do Partido Comunista Brasileiro (PCB ${ }^{6}$ às entidades que representavam os interesses da burguesia do Centro-Sul do país. As diferenças entre eles geravam conflitos que logo contribuiriam para uma ruptura da aliança desenvolvimentista. Quando o projeto original da Sudene foi lançado, porém, ele prometia realizar o sonho básico de todas aquelas correntes: unia o Estado nacional, a burguesia industrial, setores da esquerda e uma ala da Igreja - considerados os defensores do progresso - contra os latifundiários e as forças políticas locais - vistos como os representantes do atraso. Além de promover a industrialização do Nordeste, a Superintendência possuía, ainda, uma tarefa urgente: ela deveria combater a miséria e os conflitos que se espalhavam pela região, fatos que 290 eram vistos por Kubitscheck como ameaças à democracia e à soberania nacional ${ }^{7}$. Vê-se, portanto, que não era apenas nos remédios - planejamento e industrialização -, mas também nos fundamentos éticos e políticos - combate à miséria e defesa da democracia - que o então presidente concordava com Celso Furtado, um e outro com os pés fincados no terreno da ideologia desenvolvimentista. A proposta de ambos, organizada e cientificamente fundamentada por Furtado, foi capaz de transformar em interesse nacional os desejos de certas parcelas da sociedade brasileira que, juntas, se definiam como as forças do progresso. Anos mais tarde, alguns daqueles atores se viram obrigados a reconhecer, não sem pesar, que a grande beneficiada por aquela agenda foi uma fração da classe dominante em ascensão: a burguesia industrial do Centro-Sul, associada ao capital estrangeiro (Cardoso, 1978, pp. 414-16).

\footnotetext{
6 Ou Partidão, como a ele se referiam militantes e simpatizantes.

7 Segundo o ex-presidente, "a verdade é que, em torno da fermentação da miséria tornada consciente, rondam os inimigos da liberdade” (Cardoso, 1978, p. 98).
} 
Após a reunião de Petrópolis, o plano de criar uma instituição de planejamento e intervenção econômica na região Nordeste avançou. Logo o projeto e seu criador passaram a chamar a atenção da imprensa e de políticos locais que, segundo Furtado, já lhe cobravam uma parcela dos recursos que seriam destinados à nova entidade. Para encerrar as especulações, o economista concedeu uma longa entrevista ao Correio da Manhã, importante jornal do Rio de Janeiro, em que expunha com detalhes o seu plano. Editoriais publicados nas semanas seguintes contribuíram para esclarecer outros pontos do projeto, enquanto o jornalista Antônio Callado realizava uma série de reportagens sobre os problemas da região e sobre os equívocos da atenção que esta recebia do governo até aquela data. Ao denunciar a corrupção que envolvia a intervenção do Estado no Nordeste, Callado cunhou a célebre expressão "indústria das secas". Segundo Furtado, o apoio do jornal foi fundamental para que a iniciativa saísse rapidamente do papel. De um possível blefe de Kubitscheck, aquele projeto logo se tornou realidade. Com argumentos racionais apresentados em palestras e entrevistas, Furtado convencia vários setores da sociedade acerca da importância do projeto. O empresário e jornalista Assis Chateaubriand, que assistiu a uma de suas exposições no Recife, declarou: "esse é um novo Antônio Conselheiro, de fraque" (Furtado, 1989, pp. 45-51).

Furtado foi colocado na direção do novo órgão, sediado no Recife, mas vinculado diretamente à presidência da República. O economista voltava assim ao Nordeste e entrava na política regional pelo alto, sem a necessidade de se apoiar nos ombros das elites locais. Novamente um jogo de distanciamento e proximidade - tal qual aquele citado por Garcia (1998), mas agora em relação à região onde nascera - dava

\footnotetext{
8 A abordagem de Callado sobre a política nordestina entre o final dos anos 1950 e o golpe militar, em 1964, encontra-se compilada no livro Tempo de Arraes (de 1979).
} 
a Furtado uma condição singular: ele teria a oportunidade de ocupar o incômodo e cobiçado lugar de mediador entre os governadores nordestinos e o presidente da República na incessante, antiga e já viciada luta pela distribuição dos recursos da União. Tarefa nada fácil e que deveria ser realizada de acordo com as diretrizes da Sudene, ou seja, através da industrialização e do combate às desigualdades locais, medidas que se chocavam com o modelo até então aplicado. Para realizá-las, o economista contava com o apoio de um pequeno grupo de jovens servidores que atenderam ao seu chamado para trabalhar na Superintendência. Entre eles, o sociólogo Francisco de Oliveira.

\section{Francisco de Oliveira e sua "re(li)gião"}

Nascido no Recife, em 1933, filho de um comerciante e de uma dona de casa, Francisco de Oliveira se tornaria uma referência para a sociologia brasileira. Autor de ensaios impor292 tantes, como Crítica à razão dualista e Elegia para uma re(li)gião, ele realizou a maior parte de sua trajetória intelectual em São Paulo, a partir de 1969, quando passou a integrar o quadro de pesquisadores do Cebrap, liderado por Fernando Henrique Cardoso. Antes dessa fase da vida, em geral bem conhecida pelos leitores de suas obras, Oliveira teve uma rica experiência intelectual e política, repleta de conflitos e incertezas, que marcaria sua produção posterior. No final da década de 1950, à época da fundação da Sudene, ele era ainda um jovem recém-formado no então novíssimo curso de Ciências Sociais da Universidade do Recife, onde ingressou em 1952. Sobre sua graduação, ele lembra:

Estava no $3^{\circ}$ ano de Ciências Sociais e morava com meus pais. Estudava e trabalhava no Banco do Nordeste. Fui bancário dos 14 aos 21 [anos]. Quando entrei no Banco do Nordeste me dei por satisfeito. Parecia uma carreira sólida. Tínhamos seis horas de trabalho, do meio-dia às 18 
horas. Estudava à noite e lia o que dava pela manhã. Não era dramático estudar e trabalhar. Dava para conciliar. $\mathrm{Na}$ época, meu futuro não era claro para mim. O que poderia fazer com o diploma de sociólogo no Recife? (OESP, 23/11/2009).

As dúvidas sobre a carreira o levaram a pleitear postos em órgãos públicos, sobretudo na área de economia. Foi graças a um desses vínculos que o jovem sociólogo teve a oportunidade de frequentar um curso de aperfeiçoamento realizado na sede do BNDE (Banco Nacional de Desenvolvimento), no Rio de Janeiro, em 1958, sob organização da Cepal. Na ocasião, ele teve contato com as ideias desenvolvimentistas que inspiravam a criação da Sudene. No ano seguinte, quando soube que o novo órgão selecionava funcionários, Oliveira foi ao encontro de Furtado:

Eu pedi uma entrevista com ele [Furtado], que me recebeu.

"O que queria?". Eu disse que tinha sabido disso [da criação da Sudene] e que estava disposto a trabalhar. "O que você faz?". "Eu faço isso e tal, fiz o curso da Cepal, fui bem-sucedido, tive notas tais e tais". Não se comoveu, estava impassível. [...] Disse ele então: "está bem, vai falar com José Medeiros”. Era o futuro chefe de pessoal, eu estava contratado! [...] Eu, besta, assim, nunca consegui emprego tão fácil (Perruso, 2013, p. 182).

O perfil dos cerca de trinta profissionais envolvidos nas primeiras atividades do órgão é revelador: à exceção do sanitarista Mário Magalhães, com mais idade, eram todos jovens na faixa dos vinte e poucos anos, com alguma experiência em instituições públicas, a maioria natural de Pernambuco ou da Paraíba. A juventude talvez se explique pelo fato de que pessoas mais experientes, com espaço já conquistado no Centro-Sul do país, não estivessem dispostas a arriscar seus cargos por um projeto que, apesar de inte- 
ressante, parecia ainda uma grande aventura. Furtado teve, então, que recorrer aos mais jovens. Muitos deles já eram servidores públicos vinculados a instituições como o Banco do Nordeste, o Banco do Brasil ou outros órgãos estaduais de desenvolvimento. Isso ocorria porque a Sudene, ainda não legalizada, tinha dificuldades para contratar funcionários e era forçada a requisitá-los junto a outras instituições. Esse fato obrigava Furtado a contornar a carência de pessoal capacitado, sobretudo na área de economia, com um plano de treinamento dos funcionários ${ }^{9}$. As frequentes viagens que ele realizava para o Rio de Janeiro e Brasília também o levaram a logo selecionar um substituto direto em meio ao grupo ainda restrito de servidores de que dispunha. Em 1960, ele escolheu Francisco de Oliveira ${ }^{10}$, que lembra o processo e os critérios da seleção:

A certa altura o Mário Magalhães, que era uma espécie de tutor intelectual do Celso, disse a ele: "Você não pode fazer isso mais, está ficando impossível, ninguém pode administrar essa zorra aqui com você fora o tempo todo. Tem que ter um substituto". Celso concordou e foi excluindo: Luiz

\footnotetext{
9 "Um dos primeiros esforços da Sudene consistiu em formar uma equipe técnica capacitada a executar as novas tarefas de uma agência de planejamento criada para desenvolver uma região atrasada. Muitas das necessidades de pessoal técnico só poderiam ser atendidas, na própria região, com grande esforço de treinamento e formação, o que significava que os resultados só podiam surgir a médio prazo. Por isso, de imediato, foi necessário recrutar técnicos também fora da região e estruturar rapidamente um setor de treinamento sistemático e permanente. Para isso, contou-se com a participação de organismos internacionais, notadamente da Cepal, que contribuiu com seus cursos de Santiago do Chile e cursos ministrados no Brasil" (Tavares, 1989, pp. 205-206). Um primeiro curso com a participação de professores da Cepal foi oferecido para a equipe ainda em 1959. As aulas, que duravam oito horas por dia, estenderam-se por quatro meses. Seu conteúdo era semelhante àquele do curso organizado um ano antes pela Cepal, ocorrido no BNDE, do qual Francisco de Oliveira participara.

10 "Eu substituía o Celso toda hora, embora sem intervir nos assuntos de política, que era área dele. Havia uma divisão de trabalho, nunca explícita, que entendi desde o início. Minha função era fazer aquilo funcionar, e funcionava" (Jinkings, Ridenti e Maar, 2007, p. 20).
} 
Vasconcelos não podia porque era português, Jorge Furtado porque era irmão dele, Mário Magalhães não podia porque era antiburocrático. Mário me disse: "Se me entregarem esse treco, eu fecho no dia seguinte. Então sobrou para você". Eu? "É, sobrou pra você! É o mais antigo aqui depois desses três velhos, então vai você.” Foi assim que eu assumi a superintendência, em 1960, poucos meses depois do Codeno (Montero e Moura, 2009, pp. 155-56).

A Sudene nasceu e cresceu num ambiente que a transformava em algo além de um órgão técnico de intervenção sobre a região Nordeste. Ela tinha grande peso sobre o debate político e intelectual, a ponto de pautar reformas nos programas de cursos superiores em universidades locais ${ }^{11}$. Tal influência aumentou ainda mais a partir da expansão que se seguiu à aprovação de seu primeiro Plano Diretor, no final de 1961. Além de ampliar o quadro de funcionários, a Sudene lançou programas de bolsa para jovens estudantes do Nordeste. Em sintonia com os valores cultivados por Celso Furtado, cada uma das ações da Sudene deveria estar bem amparada por estudos aprofundados da realidade regional. Era imprescindível conhecer sua natureza: as bacias hidrográficas, a fertilidade do solo, as características do clima e muito mais. $\mathrm{O}$ mesmo se aplicava às particularidades de sua população: taxa de crescimento, composição etária, distribuição sobre o território. Era preciso avaliar as atividades econômicas, distribuir recursos, criar projetos. Em suma, era necessário pesquisar, e sobre uma variedade de temas que exigia a participação de diversos profissionais: geógrafos, biólogos, sociólogos, geólogos, engenheiros,

\footnotetext{
${ }^{11}$ Exemplo: segundo Perruci (1986, pp. 513-14), os cursos de desenvolvimento econômico promovidos pela Superintendência influenciaram a reforma do currículo de Ciências Sociais da Universidade do Recife a partir dos anos 1960, quando toda a instituição passaria por transformações que pretendiam alinhá-la ao contexto político nacional.
} 
demógrafos, economistas. Todos reunidos em torno de um mesmo programa que, inevitavelmente, pautou os currículos de muitos cursos antigos ou recém-criados. Além de pensar o Nordeste, a Superintendência tinha que "fazer" política, lidar com interesses diversos e negociar com os atores que pretendiam exercer maior influência sobre ela e o destino de seus recursos.

Todas essas peculiaridades e a amplitude de suas atividades são indícios do papel que ela teve na formação intelectual e política do jovem Francisco de Oliveira. Quando ele ingressou na Sudene para trabalhar ao lado de Celso Furtado, já possuía uma experiência de militância no Partido Socialista Brasileiro (PSB), com o qual tinha contato desde os tempos de movimento estudantil. Embora essa organização não tivesse naquele momento a mesma importância atribuída ao PCB, seu peso na política pernambucana não pode ser negligenciado. Entre seus quadros, o maior destaque cabia 296 a Francisco Julião, advogado vinculado às Ligas Camponesas e conhecido como sua principal liderança. Ambos, Oliveira e Julião, eram amigos, de tal modo que o jovem sociólogo foi quem datilografou Cambão, livro que o advogado escreveu enquanto os dois se encontravam exilados no México, já depois de 1964. Não há, porém, sinais de que a amizade com Julião ou o contato com o PSB tenham levado Oliveira a realizar alguma atividade política orientada no interior da Sudene $^{12}$. Talvez porque nenhuma bandeira vinculada a tal partido convencesse mais do que as ideias de Furtado.

A Superintendência não era apenas permeada pelo discurso desenvolvimentista; ela também contribuía para a formulação e difusão desse ideário. O recrutamento dos seus quadros obedecia a critérios técnicos, mas também demandava uma parcela de paixão. Sem a crença no pro-

\footnotetext{
${ }^{12}$ Os dados a respeito de sua militância no PSB são escassos. Nos inúmeros depoimentos consultados, Oliveira não dá muito destaque a essa experiência.
} 
jeto desenvolvimentista de Furtado, como dezenas de profissionais com bom nível de formação, alguns deles com mercado de trabalho aberto no Sudeste do país, aceitariam se instalar no Recife, num projeto inteiramente novo e tão dependente das oscilações da política nacional e regional? Ainda que tal crença aparecesse como uma aposta racional vinculada à noção de planejamento econômico e às suas promessas, ela provavelmente não teria tamanho poder sem um aspecto em certo sentido religioso: a "questão regional" e o desenvolvimento eram para muitos daqueles profissionais uma paixão. A região era uma "religião", como alude o título de um livro de Oliveira publicado anos depois ${ }^{13} \mathrm{E}$, uma vez dentro da Sudene, esse grau de comprometimento tendia a aumentar. As atividades iniciais do órgão consistiam, sobretudo, em treinamento de pessoal e pesquisas, já que as verbas necessárias para a execução dos projetos não apareceriam antes de 1961, com a aprovação do Plano Diretor. O quadro de funcionários também crescia lentamente, sempre limitado pelo orçamento. Durante os primeiros anos, portanto, o grupo era menor e mais coeso do que seria a partir da grande expansão que se seguiu à ampliação de suas verbas. O convívio diário, temperado pelo conflito com forças políticas externas, estimulava essa coesão interna, bem como os seminários e cursos de formação. Assim, a Sudene pode ter ocupado, pelo menos nos primeiros anos, um espaço semelhante ao de um partido político na vida de Francisco de Oliveira, entre outros funcionários do órgão.

Contudo, há vários sinais de que essa relação não foi sempre a mesma, sobretudo a partir do processo de expansão iniciado em 1961. A esse fato interno, somaram-se eventos

\footnotetext{
13 Trata-se de Elegia para uma re(li)gião, lançado em 1977, onde o autor analisa a experiência da Sudene. O caráter apaixonado de seu envolvimento com a Superintendência e de sua relação com o Nordeste fica ainda mais evidente a partir da leitura de A noiva da revolução, relato sentimental sobre o Recife publicado junto com a reedição de Elegia... (Oliveira, 2008).
} 
internacionais, nacionais e regionais que acirraram o debate político em torno da instituição. Todos esses fatores contribuíram para que aquela coesão interna, de um grupo relativamente pequeno e homogêneo, desaparecesse. Esse movimento e o golpe de 1964, analisados a seguir, afetariam de maneira definitiva as trajetórias de Celso Furtado e de Francisco de Oliveira.

\section{0 fim da fantasia}

Nota-se, observando o debate que envolveu a criação da Sudene, no final dos anos 1950, que a criação do órgão significou considerável mudança na forma como o Estado brasileiro encarava as desigualdades regionais. Até aquele momento, apesar de intensas lutas sociais que se espalharam pelo Nordeste desde o tempo do Império, “a questão regional foi percebida, formulada e enfrentada, sobretudo, em função dos interesses da elite regional" (Bernardes, 298 2007, pp. 69-70; grifo no original). A atuação mais livre de partidos e movimentos sociais após o fim do Estado Novo, em 1945, gerou maior consciência a respeito dos problemas decorrentes da concentração de terras. "Não bastava mais o tradicional combate às secas, que até então apenas beneficiara a grande propriedade e nada alterara da miséria rural" (Bernardes, 2007, pp. 69-70). Esse deslocamento da preocupação com a "questão regional" das elites para os movimentos populares é bem exemplificado pela articulação de forças políticas e sociais que resultou na realização do Congresso para a Salvação do Nordeste, em 1955:

[...] organizado por iniciativa da seção de Pernambuco da Liga de Emancipação Nacional, e, segundo Paulo Cavalcanti ${ }^{14}$, idealizado pelo Partido Comunista, foi um

\footnotetext{
${ }^{14}$ Deputado estadual comunista, figura importante do PCB no Estado de Pernambuco.
} 
importante instrumento para introduzir no Nordeste as teses desenvolvimentistas apoiadas pela esquerda e por setores da burguesia, ampliar os espaços dos movimentos populares, bem como encaminhá-los para uma perspectiva de luta nos marcos econômicos-institucionais dominantes (Soares, 1982, p. 44).

Assim, em 1959, quando Celso Furtado ganhou as páginas da imprensa com a sua Operação Nordeste, as opiniões favoráveis a ele e às suas ideias eram amplamente majoritárias. O apoio surgia de setores à esquerda e à direita, de movimentos sociais e da burguesia do Centro-Sul ou frações renovadas da oligarquia nordestina, da Igreja, do governo federal e até mesmo de representantes do governo dos Estados Unidos. Em resumo: à exceção da oligarquia açucareira, em declínio, Furtado e seu projeto eram uma unanimidade. Porém, esse quase consenso se desfez rapidamente. $\mathrm{O}$ ano de 1961, apontado por Francisco de Oliveira (2008, p. 238) como aquele em que o proletariado pernambucano passou a comandar a coligação de forças em torno da Frente do Recife $^{15}$, também serve de divisor de águas quando o assunto é a imagem da Sudene diante dos vários setores da sociedade que apostavam em seu projeto.

Em julho daquele ano, Furtado foi convidado para uma visita oficial aos Estados Unidos, onde foi recebido pelos presidentes da Fundação Ford e do Banco Mundial, além do Presidente John Kennedy. Essa viagem é um bom exemplo da fama internacional que a experiência da Sudene conquistara e da aposta que se fazia em sua capacidade de minorar

${ }^{15}$ Criada em 1955 em apoio à candidatura vitoriosa de Pelópidas da Silveira, a Frente do Recife era uma aliança entre diversas forças políticas locais, nas quais os trabalhadores ocupavam, a princípio, um lugar subalterno (Bernardes, 2007, pp. 70-71). Esse quadro começou a mudar a partir da eleição de Arraes para a Prefeitura do Recife, em 1959, pelo Partido Social Democrático (PSD), integrante da Frente. A ascensão dos setores de esquerda no interior da aliança se confirma em 1962, quando Arraes é eleito governador, filiado ao pequeno Partido Social Trabalhista (PST). 
os problemas do Nordeste brasileiro e, assim, evitar qualquer risco revolucionário na região. $\mathrm{O}$ apoio do governo dos Estados Unidos ao plano quinquenal da Superintendência, que previa um generoso aporte financeiro, justificava-se, sobretudo, pelo incentivo a projetos que pretendiam atender às demandas mais imediatas dos trabalhadores rurais, de tal modo que sufocasse o avanço de movimentos radicais organizados, como as Ligas Camponesas. Era necessário esvaziar o barril de pólvora. No ano seguinte, porém, o programa Aliança para o Progresso chegou ao Nordeste com funcionários e uma agenda própria que, em muitos casos, chocava-se com os planos da Sudene ${ }^{16}$. Sem acordo com Furtado, o chefe da missão estadunidense passou a negociar projetos diretamente com os governadores locais. Essa mudança de atitude do governo dos Estados Unidos pode ser creditada, entre outros motivos, à radicalização do movimento revolucionário em Cuba, no plano internacional, e, no plano interno, ao aque300 cimento do debate sobre as Reformas de Base a partir da posse de João Goulart, no final de 1961, e ao crescimento da esquerda durante os governos de Miguel Arraes, na capital e no Estado de Pernambuco. Todos esses avanços de forças políticas à esquerda apareciam como um sinal de que algumas reformas, como as defendidas por Furtado, poderiam alimentar novos processos revolucionários no continente.

Mas não foi apenas o apoio norte-americano que desapareceu. À esquerda, a confiança na Sudene também diminuía. A viagem de Furtado aos Estados Unidos e o apoio que recebera desse país, num primeiro momento, foram mal vistos pelo $\mathrm{PCB}$, que desconfiava de qualquer relação com

\footnotetext{
${ }^{16}$ Aliança para o Progresso foi um programa do governo Kennedy, que visava à integração e ao desenvolvimento do continente americano, com aportes financeiros aos países da América Latina, de modo a conter os movimentos sociais e a expansão do comunismo. O programa foi lançado em 13 de março de 1961 e ratificado em 16 de agosto na Carta de Punta Del Este, Uruguai, onde 22 países latino-americanos o assinaram, exceto os ausentes Canadá e Cuba.
} 
o "imperialismo"17. Ao mesmo tempo, as Ligas Camponesas exerciam crescente pressão pela resolução da questão fundiária, problema que não figurava entre as prioridades do programa da Superintendência. De acordo com Francisco de Oliveira e outros ex-funcionários do órgão entrevistados, Furtado tinha consciência da centralidade da pauta da reforma agrária, mas preferiu adiá-la com o temor de que um enfrentamento direto com a oligarquia poderia decretar o fim precoce da experiência da Sudene. Apesar da cautela, os setores oligárquicos nunca deixaram de suspeitar dos planos de Furtado, o que se refletia nas críticas cada vez mais frequentes que os jornais ligados aos grandes proprietários de terra direcionavam a ele. Num primeiro momento, antes do início da execução de seus projetos, a Sudene era acusada de ser um espaço de muito pensamento e pouca ação. Quando o trabalho deslanchou, ela começou a ser censurada por supostamente executar, aos poucos, o programa da esquerda. A situação era paradoxal: se, por um lado, o PCB suspeitava dos diálogos de Furtado com os Estados Unidos, de outro a elite regional julgava que a Sudene era uma instituição dominada por comunistas. Assim, na esteira de um acirramento da luta de classes, o enorme apoio inicial se convertia numa difícil encruzilhada.

Essas mudanças nas relações entre as forças políticas coincidem com o período de expansão da Superintendência. De acordo com alguns depoimentos, a Sudene contava com cerca de 2 mil funcionários no momento do golpe militar. Um efeito de seu crescimento foi que ela se viu cada vez mais imersa no "furacão" em que se transformara

\footnotetext{
${ }^{17}$ Num artigo assinado por Josué Almeida (1961) no jornal Novos Rumos, do Partidão, lê-se: "Quando o sr. Celso Furtado esteve nos Estados Unidos, pleiteando dólares para a Sudene, não lhe perguntaram se o que pedia era bastante para proporcionar leite às crianças do Nordeste, ou se o programa agrário da Sudene atenderia às reivindicações da massa camponesa sem terra. Perguntaram-lhe, sim, se o Plano da Sudene afastaria o 'perigo' do comunismo e do castrismo no Nordeste, que é este e não a fome que tira o sono dos alegres milionários ianques".
} 
a conjuntura política brasileira, nordestina, em particular a pernambucana. Entre seus quadros já existiam algumas pessoas com relações próximas ao PCB ou ao governo de Miguel Arraes. Este é o caso de Jader Andrade, membro do grupo inicial da Codene, que estava à frente da diretoria de política agrária. Andrade assumiria pouco depois a Secretaria de Agricultura de Pernambuco na gestão de Arraes. Ele era amigo de Francisco de Oliveira desde o período em que os dois trabalharam juntos no Banco do Nordeste, ainda antes da criação da Sudene. Outro funcionário próximo dos comunistas era Nailton Santos, irmão do geógrafo Milton Santos, responsável pelo setor de recursos humanos.

Esses são apenas dois exemplos de quadros que ocupavam postos de destaque na Sudene e que tinham estreita relação com a esquerda comunista. É possível imaginar, então, que muitos entre os novos técnicos contratados no período de expansão tinham algum contato ou simpatia pelo PCB 302 ou outras forças políticas à esquerda. A mudança de clima favorecia o surgimento de fatos inéditos, como um movimento liderado por servidores mais novos, organizados numa associação, que ensaiou uma greve para reivindicar maiores salários. O conflito interno era, sem dúvida, uma reprodução dos debates que envolviam duas importantes vertentes do nacional-desenvolvimentismo: a pública e nacionalista, de que Celso Furtado era um dos maiores expoentes, e a socialista, da qual muitos servidores da Sudene eram próximos ${ }^{18}$. Tudo isso pouco antes do golpe de 1964. A aliança nacional-desenvolvimentista se desmanchava.

E qual era a posição de Francisco de Oliveira, o segundo na hierarquia da Sudene, diante dessa agitação? Começo a responder a essa questão com uma descrição, sem dúvida, exagerada, encontrada num perfil de Oliveira elaborado

\footnotetext{
${ }^{18}$ Faço referência a duas vertentes citadas por Bielschowsky (2004, pp. 33-34), em sua tipologia das correntes nacional-desenvolvimentistas.
} 
pelos militares e reproduzido na íntegra, a partir das páginas de um Inquérito Policial Militar:

- Responsável pela Cubanização da Sudene. Em discurso proferido em banquete de posse de Jader Andrade na SAIC, referiu-se à "luta comum" que vinham travando desde os bancos escolares. Chegou a brigar com Celso Furtado porque este não estava dentro da linha, pois achava que ele estava fazendo o jogo dos americanos nos arts. 18 e 34 do Plano Diretor da Sudene. Ele, Jader de Andrade e Juarez Farias, formavam uma "panelinha" que ditava as metas políticas, com a complacência de Celso Furtado, comportando-se este, dubiamente, sem se definir, porém fazendo jogo de sua conveniência pessoal. Francisco de Oliveira era o homem que acolhia as reivindicações "subversivas" dos funcionários esquerdistas e das Associações dos Servidores da Sudene, junto à Superintendência. A Diretoria da Associação estava dominada por agitadores. Era o "quebra-galho" dos esquerdistas junto ao próprio Superintendente. Aproveitava, quando assumia a Superintendência, para agir mais objetivamente. Os servidores esquerdistas da Sudene estavam dispostos a cerrarem fileiras ao lado de Francisco de Oliveira contra Celso Furtado, no caso citado pela demissão de funcionários reconhecidamente subversivos, entre eles, Pedro Mota Barros, que foi indicado por Francisco Oliveira, para trabalhar na Sudene.

- Preso em 09 Abr 64, e recolhido ao Hospital Militar.

- Assinante do manifesto de apoio a Arraes. ${ }^{19}$

${ }^{19}$ Perfil atribuído a "Francisco Maria Cavalcanti de Oliveira", localizado no arquivo digitalizado pelo projeto Brasil: Nunca Mais, Arquivo BNM 266, p. 5154. 
Sabe-se que o material produzido pelos militares é repleto de exageros e equívocos. Ainda assim há dados aí que não podem ser ignorados. É interessante notar que o relatório sugere a existência de conflitos entre Furtado e Oliveira e ainda destaca a relação próxima que este tinha com Jader Andrade, ligado ao PCB. Para os militares, o sociólogo teria um perfil "subversivo" mais evidente do que Furtado. Oliveira é apontado, inicialmente, como o mediador responsável por levar as posições dos "esquerdistas" ao superintendente. Em seguida, aparece como um dos líderes dessa ala. É difícil saber até que ponto essas informações são confiáveis ou quais são os fatos e fontes em que se basearam os militares para chegarem a essas conclusões. Decidi explorar o tema em algumas das entrevistas realizadas com ex-funcionários da Sudene, que confirmaram a proximidade entre Francisco de Oliveira e Jader Andrade. Ao lado de Nailton Santos, ambos estariam 304 entre os mais visados pela repressão após o golpe de 1964 e, depois de presos, dividiram a mesma cela.

Há, portanto, uma razoável precisão nas informações contidas no perfil de Francisco de Oliveira elaborado pelos militares. E o dado mais impressionante de seu conteúdo é outro: segundo o inquérito, Oliveira teria "brigado" com Celso Furtado por causa dos artigos 18 e 34 do Plano Diretor da Sudene, por meio dos quais o economista "estaria fazendo o jogo dos americanos" ${ }^{20}$. Decidi destacar essa informação porque ela antecipa, ainda em $1964,{ }^{21}$ um ponto de discórdia entre Furtado e Oliveira que reapareceria em suas análises posteriores sobre a experiência da Superintendência: o famoso mecanismo $34 / 18^{22}$, apontado por muitos críticos como o grande responsável pela entrada

\footnotetext{
${ }^{20}$ Citado no Arquivo BNM 266, página 5154.

${ }^{21}$ Não foi possível precisar a data em que esse relatório militar foi elaborado, mas tudo indica que tenha sido entre abril e setembro de 1964 .

${ }^{22}$ Refere-se aos artigos 18 e 34 mencionados.
} 
de capitais do Centro-Sul e de empresas estrangeiras no Nordeste $^{23}$. Inspirado pela legislação italiana da Cassa del Mezzogiorno, que pretendia incentivar a industrialização do sul daquele país, esse mecanismo surgiu no Brasil graças à necessidade de direcionar capital ao Nordeste e à Sudene, até então bastante carente de recursos. Quando ele foi aprovado, Furtado pensava que:

Estava dado o passo inicial de uma política que certamente envolvia riscos, mas que foi decisiva para impulsionar a industrialização da região. Era como se o Estado dissesse aos empresários de todo o país: aquele que investir no Nordeste obterá um financiamento a fundo perdido correspondente à metade da aplicação feita. Mas estabelecia uma condição: este investimento terá de enquadrar-se na política de desenvolvimento regional definida pela Sudene. Em realidade, cada projeto teria de ser aprovado por esse órgão, e os desembolsos, supervisionados em função da execução da obra (Furtado, 1989, p. 121).

De fato, através dessa legislação empresas detentoras de grande capital - a maioria do Centro-Sul do país - foram incentivadas a investir no Nordeste em troca de isenções fiscais. Realizava-se, assim, o plano de integrar a economia regional à nacional, o que ocorria, porém, sem alterar a relação de subordinação já existente, pois o capital apenas passava pelo Nordeste e em seguida voltava para o centro do sistema, dentro ou fora do país, sobretudo a partir da aprovação de uma modificação, em 1963, que suprimia a exigência de $100 \%$ de capital nacional para a participação no programa de isenção fiscal. O Estado descartava, assim, uma parcela considerável de tributos

${ }^{23}$ Essa crítica aparece num artigo de 1973, escrito em parceria com o economista Henri Philippe Reichstul, e retomada em Elegia para uma re(li)gião, em 1977. Ver Oliveira e Reichstul (1973). 
a serem captados, e os mantinha, enquanto capital, nas mãos dos grandes investidores.

A apreciação desse mecanismo é um dos pilares de Elegia para uma re(li)gião e outros textos de Francisco de Oliveira dedicados a rever a trajetória da Superintendência e suas consequências. Como os militares souberam da existência desse debate? É certo que ele ocorria dentro e fora da Sudene, pois esse órgão não estava imune ao intenso conflito político que se desenvolvia no Recife. Reuniões de servidores com políticos e representantes de movimentos sociais poderiam alimentar discussões sobre algumas medidas dentro da Superintendência, embora todos os relatos indiquem que ninguém, nem mesmo Francisco de Oliveira, questionava a política posta em prática por Furtado. Talvez a "briga" entre ambos nunca tenha ocorrido, e sua inserção no relatório militar sirva apenas como um elemento a mais para pintar o sociólogo como um subversivo ${ }^{24}$. De qualquer modo, 306 Oliveira lembrou, numa entrevista, que tinha bastante contato com Miguel Arraes. Quando voltava ao Recife após as muitas viagens que fazia ao Rio de Janeiro e à Brasília pela Sudene, Oliveira passava pela casa do governador para trocar impressões sobre o cenário nacional e, sem dúvida, ouvia opiniões e talvez cobranças a respeito de Furtado e de seu programa ${ }^{25}$. É provável que o mecanismo 34/18 tenha sido tema de alguns desses encontros, ainda que os representantes da esquerda nordestina não fossem tão críticos a tal mecanismo àquela altura, já que seu efeito imediato - a entrada de capital do Centro-Sul para promover a industrialização do Nordeste - não contrariava o programa de aliança com a burguesia nacional amplamente defendido.

\footnotetext{
${ }^{24}$ Mostrei esse perfil a Francisco de Oliveira durante uma entrevista realizada em abril de 2015. O sociólogo ainda não conhecia o material e riu de seu conteúdo, o qual considerou uma "grande bobagem".

${ }_{25}$ "Eu viajava muito a trabalho e tentava passar informações ao Arraes, que era o político com quem eu tinha maior relação" (Jinkings, Ridenti e Maar, 2007, p. 24).
} 
De qualquer modo, o conhecimento da existência de conflitos internos na Sudene, até hoje pouco explorados, pode contribuir para a compreensão da rápida mudança na trajetória de Francisco de Oliveira após o golpe de 1964, quando transitou, num curto espaço do tempo, do nacional-desenvolvimentismo para o marxismo. Se ele mantinha contato com o PCB ou outras forças políticas de esquerda, ainda que de forma não orgânica, sem dúvida já era capaz de criticar algumas das posições defendidas por Celso Furtado ${ }^{26}$. Este é um dado interessante, mesmo quando se considera que um possível distanciamento não poderia extrapolar os limites da ideologia nacional-desenvolvimentista, compartilhada também pelo Partidão. Esse fato não impediu que após a ruptura de 1964 e a derrota daquele projeto, Oliveira buscasse respostas à esquerda que o ajudassem a compreender o que havia ocorrido ${ }^{27}$.

Sabe-se que a solução conservadora encontrada para aquela enorme crise, de raízes profundas no Nordeste, foi um golpe liderado pelos militares com expressivo apoio de setores civis. Francisco de Oliveira, que se encontrava no Recife quando o movimento golpista começou, seguiu com Celso Furtado para o Palácio do Governo de Pernambuco, residência oficial do governador Miguel Arraes. O sociólogo descreve aquelas horas de tensão:

Eu assisti toda a negociação, da tarde do dia 31 de março até o dia $1^{\circ}$ de abril, e os milicos também não sabiam o que

\footnotetext{
${ }^{26}$ Em Elegia para uma re(li)gião, ele escreveu: "Pertencente aos quadros da Sudene desde sua fundação até o ano de 1964, estive em posição privilegiada vendo, participando, dissentindo, perdendo dentro do processo" (Oliveira, 2008, p. 126). A parte final da frase, que grifei, sugere a existência de conflitos.

${ }^{27}$ Sinais de uma mudança de perspectiva apareceram muito antes de sua entrada para o Cebrap, no final dos anos 1960. No artigo "Condições institucionais do planejamento" - publicado na revista Civilização Brasileira, em 1966 - o sociólogo apresenta uma dura crítica ao pensamento da Cepal, porém sem a consistência que marcará seus textos da década seguinte. Em entrevista recente, Oliveira comentou o conteúdo desse artigo: "Já era um pé atrás com o furtadismo que fazia do planejamento uma espécie de panaceia” (Ridenti e Mendes, 2012, p. 602).
} 
fazer. Celso Furtado foi para lá, demos a colaboração que a gente podia. Os aviões para contatar os governadores eram aviões da Sudene, por exemplo. Eu vi quando o coronel Dutra de Castilho deu ordem de prisão a Arraes. Ninguém me contou, eu vi (Montero e Moura, 2009, pp. 160-62).

Poucos dias depois, os caminhos dos colegas de Sudene seriam redefinidos pela repressão: no dia 6 de abril, após um jantar de despedida de Celso Furtado, que decidira deixar o Recife, Oliveira voltou para casa e foi acordado de madrugada por policiais civis. Detido, foi levado ao gabinete do delegado Álvaro da Costa Lima. Enquanto Furtado partia para o exílio, Oliveira ia para a prisão no Recife, onde permaneceria por dois meses ${ }^{28}$.

$\mathrm{O}$ início da ditadura interrompeu repentinamente a experiência da Sudene e impôs mudanças na vida dos envolvidos naquele projeto. A Superintendência continuaria a 308 existir, mas seu caráter seria modificado de forma profunda e irreversível. Para muitos dos que a conheceram antes e depois do golpe, ela foi finalmente capaz de executar o programa de industrialização concebido por Furtado, mas já desprovido do conjunto de reformas que o complementava no projeto original. Obrigado a abandonar seu plano, o economista se exilou em Santiago, capital do Chile, logo após o golpe, e de lá seguiu para a França, onde passou a lecionar. Oliveira também foi para o Chile depois de sair da prisão, mas, sem espaço naquele país, decidiu seguir para a Guatemala e finalmente para o México, onde atuou como pesquisador e professor durante dois anos. Voltou ao Brasil apenas no final dos anos 1960, quando, graças a um convite

\footnotetext{
${ }^{28}$ Para reproduzir esses acontecimentos, me baseio em relatos de Francisco de Oliveira encontrados em diversas entrevistas, nas lembranças de Celso Furtado (1989, pp. 190-201) e em entrevistas com ex-servidores da Sudene. Sobre as datas e fatos, há divergências, já que os personagens são por vezes traídos pela memória. Decidi usar as que mais se repetem ou aquelas que constam em documentos militares.
} 
de Octavio Ianni, entrou para o recém-criado Cebrap, onde se consolidou como um dos mais influentes intelectuais na luta contra a ditadura. Tanto que, ao recordar a interrupção forçada de sua trajetória na Sudene, o sociólogo nos fornece um depoimento curioso:

É paradoxal: 1964 me salvou de ser um burocrata de êxito. Quer dizer, o que foi ruim para o país [,] para mim foi bom. Quer dizer, foi bom vendo em perspectiva, jamais ia adivinhar nada disso, porque eu estava numa carreira ascendente, e isso felizmente não aconteceu. Mas o impacto foi destrutivo. Calou fundo no Nordeste, o que até hoje é pouco explorado. Calou fundo [a] ponto de que Celso tornou-se um dom Sebastião. Foi uma frustração enorme e, eu diria, irrecuperável (Montero e Moura, 2009, p. 162).

O golpe de 1964 não interrompeu apenas projetos políticos como aquele que suportou a criação da Sudene. A chegada dos militares ao poder obrigou muitos personagens a reverem suas trajetórias e a se adaptarem à nova realidade a partir dos recursos que tinham à disposição. As experiências expostas neste artigo servem de exemplo: de um lado, Celso Furtado - ao mesmo tempo, um economista de renome internacional e um ator político de peso no Brasil - viu-se forçado a abandonar sua carreira pública e a abraçar, no exílio, seu prestígio intelectual; de outro lado, Francisco de Oliveira - à época, ainda um jovem e desconhecido servidor público - teve a chance de redefinir sua atuação, ao deixar de lado a carreira de economista vinculado à burocracia estatal e retomar os estudos de sociologia que o conduziram, não sem obstáculos, a um lugar de destaque no campo intelectual de oposição à ditadura.

Diferenças à parte, essas duas experiências de vida, retomadas e comparadas aqui, ajudam a revelar novos aspectos dos conflitos externos e internos que envolveram a criação 
da Sudene e sua crise, bem como a ascensão e o declínio do nacional-desenvolvimentismo às vésperas do golpe de 1964. Como lembrou Francisco de Oliveira, aquele evento "calou fundo" na trajetória de muitos personagens e na realidade do Nordeste e do país. Há, portanto, ainda muito a se estudar a respeito dessa época.

\section{Flávio da Silva Mendes}

é pós-doutorando em Sociologia na Universidade Estadual de Campinas (Unicamp).

\section{Bibliografia}

ALMEIDA, J. 1961. “Ajuda” americana e política independente. Novos Rumos, 6 out.

BERNARDES, D. M. 2007. Notas sobre a formação social do Nordeste. Lua Nova, n. 71, pp. 41-79.

BIELSCHOWSKY, R. 2004. Pensamento econômico brasileiro. O ciclo ideológico do desenvolvimentismo. Rio de Janeiro: Contraponto.

310 BRASIL: NUNCA MAIS [projeto]. Arquivo BNM 266, p. 5154. Disponível em: <http://bnmdigital.mpf.mp.br/DocReader/docreader. aspx?bib=BIB_03\&PagFis=76809>. Acesso em: 10 mar. 2017.

CALlADO, A. (1979). Tempo de Arraes. A revolução sem violência. Rio de Janeiro: Paz e Terra.

CARDOSO, M. L. 1978. Ideologia do desenvolvimento. Brasil: JK-JQ. Rio de Janeiro: Paz e Terra.

FURTADO, C. 1960. Operação nordeste. Rio de Janeiro: Iseb. 1980 [1959]. Formação econômica do Brasil. São Paulo: Ed. Nacional. 1989. A fantasia desfeita. São Paulo: Paz e Terra. 1992. Brasil, a construção interrompida. Rio de Janeiro: Paz e Terra.

GARCIA, A. 1998. La construction interrompue. Celso Furtado, la guerre froide et le développement du Nordeste. Actes de la Recherche en Sciences Sociales, n. 121-22, pp. 52-61.

JINKINGS, I.; RIDENTI, M.; MAAR, W. L. 2007. Entrevista: Francisco de Oliveira. Margem Esquerda, São Paulo, Boitempo, n. 10, pp. 13-37.

LOUREIRO, M. R. G. 1997. Os economistas no governo: gestão econômica e democracia. Rio de Janeiro: Ed. FGV.

MANTEGA, G. 1984. A economia política brasileira. Rio de Janeiro: Polis/ Vozes. 
MENDES, F. S. 2015. O ovo do ornitorrinco: a trajetória de Francisco de Oliveira.

Tese de doutorado em Sociologia. Campinas: IFCH, Unicamp.

MONTERO, P.; MOURA, F. (orgs.). 2009. Retrato de grupo: 40 anos do Cebrap. São Paulo: Cosac Naify.

OESP - O Estado de S. Paulo, 23 nov. 2009. O sociólogo Francisco de

Oliveira fala o que queria saber aos 21 anos.

OLIVEIRA, F. 1966. Condições institucionais do planejamento. Revista

Civilização Brasileira, Rio de Janeiro, v. 5-6, pp. 39-47. . 2003. Crítica à razão dualista / O ornitorrinco. São Paulo: Boitempo. . 2008. A noiva da revolução / Elegia para uma re(li)gião [1977]. São

Paulo: Boitempo. 2009. Depoimento na CPI sobre a Sudene (1978). In: FURTADO,

R. O Nordeste e a saga da Sudene. Rio de Janeiro: Contraponto.

OLIVEIRA, F.; REICHSTUL, H. P. 1973. Mudanças na divisão interregional do trabalho no Brasil. Estudos Cebrap, v. 4, pp. 131-68.

PERRUCI, G. 1986. Um projeto oligárquico-liberal de universidade (notas para uma história da UFPE). Cadernos de Estudos Sociais, Recife, v. 2, n. 2, pp. 505-20.

PERRUSO, M. A. 2013. Uma trajetória dissonante: Francisco de Oliveira, a Sudene e o Cebrap. Caderno CRH, Salvador, v. 26, n. 67, pp. 179-92.

RIDENTI, M. S.; MENDES, F. S. 2012. Do dualismo ao ornitorrinco:

entrevista com Francisco de Oliveira. Caderno CRH, Salvador, v. 25, n. 66, pp. 601-22.

SOARES, J. A. 1982. A Frente do Recife e o governo Arraes. Rio de Janeiro: Paz e Terra.

TAVARES, H. M. 1989. Uma experiência de planejamento regional: o Nordeste brasileiro. Tese de doutorado em Economia. Campinas: IE, Unicamp. 


\section{NO OLHO DO FURACÃO: CELSO FURTADO E FRANCISCO DE OLIVEIRA NOS PRIMEIROS ANOS DA SUDENE}

\section{FLÁVIO DA SILVA MENDES}

Resumo: Neste artigo, retomo a história da criação da Superintendência para o Desenvolvimento do Nordeste (Sudene), em 1959, e seus primeiros anos até o golpe de 1964. Para tanto, destaco as trajetórias de dois de seus personagens: Celso Furtado e Francisco de Oliveira. O primeiro, economista já consagrado à época, foi quem concebeu e apresentou o projeto da Sudene ao então presidente Juscelino Kubitschek, de quem recebeu a tarefa de dirigir a nova entidade. O segundo, então um jovem sociólogo recifense, chegou à Superintendência como membro da pequena primeira equipe de trabalho e se tornou, pouco depois, o substituto direito de Furtado. Ao longo do texto, demonstro como essa breve e intensa experiência, interrompida à força em 1964, marcou as trajetórias desses dois importantes intelectuais brasileiros do século XX.

Palavras-chave: Celso Furtado; Francisco de Oliveira; Sudene.

\section{IN THE EYE OF THE HURRICANE: CELSO FURTADO AND FRANCISCO DE OLIVEIRA IN SUDENE'S EARLY YEARS}

Abstract: This article resumes the creation story of the Superintendência para o Desenvolvimento do Nordeste (Sudene) in 1959, since its early years until the military coup in 1964. Therefore, it is relevant to highlight the trajectories of two characters in this process: Celso Furtado and Francisco de Oliveira. The first one was a well-known established economist at the time. He conceived and presented the Sudene's project to President Juscelino Kubitschek, who gave him the task of managing the new entity. The second one, a young sociologist from Recife, came to the Sudene as a member of the first workgroup and shortly later became 
Furtado's substitute. Throughout the text, we demonstrate how this brief and intense experience - sharply interrupted in 1964 - became remarkable in the trajectories of these two important Brazilian intellectuals of the $20^{\text {th }}$ century.

Keywords: Celso Furtado; Francisco de Oliveira; Sudene.

Recebido: 18/05/2016 Aprovado: 26/01/2017 